\title{
Resistência e elasticidade de concretos compactados com agregados reciclados de construção e de demolição para aplicações em pavimentação
}

\author{
Gino Ricci ${ }^{1}$; José Tadeu Balbo ${ }^{2}$
}

\begin{abstract}
Resumo: O emprego de agregados reciclados de resíduos sólidos da construção civil e demolição tem sido objeto de interesse de agentes públicos engajados em projetos e obras de pavimentação viária. A coleta, triagem e classificação desses materiais como agregados alternativos torna ainda possível seu emprego em concretos para algumas finalidades, sendo que no caso do concreto compactado para fins de pavimentação ainda não se tem precedente de uso no país. Estudos sobre este material para pavimentação têm sido realizados, sendo aqui apresentados resultados relativos a características mecânicas fundamentais para a análise das potencialidades do material para bases de pavimentos asfálticos e de concreto, ainda que para aplicações urbanas e em volumes limitados. Foram empregados nos estudos agregados reciclados de diferentes origens em substituição parcial ou total dos de agregados nos concretos. Os resultados obtidos permitem observar inexpressiva alteração em resistências com pequenos ajustes nos consumos de cimento. Todavia, concomitantemente ocorreu queda expressiva dos valores de módulo de elasticidade dos materiais na medida em que frações menos densas de agregados foram empregadas em maior quantidade e a parcela de substituição de agregados virgens por reciclados aumentou. As características observadas permitem a indicação do emprego do material para vias de baixo volume de tráfego além de áreas residenciais, condomínios, estacionamentos, etc. Por outro lado, o aumento da porosidade dos concretos em função da presença de reciclados exige atenção e estudos mais aprofundados sobre o comportamento à fratura e à fadiga desses materiais.
\end{abstract}

\begin{abstract}
Along the last decades, recycled aggregate produced from waste material from civil construction activities gained growing interest for its employment in pavements. Appropriate collection, selection and sieving of such a material make it possible to use it in concretes for many applications, such as rolled compacted concrete. As partial results of an in course comprehensive study about compacted concrete, manufactured with this kind of aggregate, essential physical and mechanical characteristics of some concretes are presented herein, promptly aiding to foresee its suitability as bases for asphalt or concrete pavements, despite the constrained context. Recycled aggregate from several sources has been used as a replacement for coarse and fine aggregates in concretes. Results went beyond expectations since the little cement content increases requirements to avoid strength losses as pottery recycled aggregates contents also increase. However, the concrete modulus of elasticity has fallen with the inclusion of alternative aggregate. The set of results allow indicating that such concretes can be used in low-volume pavements such as residential ones, parking lots, garage floors, among others; nevertheless, the increasing porosity of the compacted concretes using recycled aggregate needs further attention as regards to fatigue and fracture of such materials for paving purposes.
\end{abstract}

\section{INTRODUÇÃO}

O emprego de agregados reciclados a partir de resíduos de demolição de edifícios e de pontes na Europa se deu de maneira ampla durante inúmeras obras de reconstrução nos anos que se seguiram o final da Segunda Guerra. Mais remotamente ainda, na construção de vias urbanas, resíduos de materiais cerâmicos e de agregados foram fartamente empregados pelos construtores romanos na pavimentação de vias urbanas em estratos inferiores dos pavimentos (Bolis e Di Renzo, 1949). No Brasil, somente a partir de 2002, o Conselho Nacional do Meio Ambiente estabeleceu as diretrizes, critérios e procedimentos para a gestão dos resíduos da construção civil (CONAMA, 2002), muito embora experiências isoladas com emprego de resíduos de construção e de demolição (RCD) viessem

\footnotetext{
${ }^{1}$ Gino Ricci, Universidade Bandeirante, São Paulo, SP, Brasil. (e-mail: ricci2@uol.com.br).

${ }^{2}$ José Tadeu Balbo, Universidade de São Paulo, São Paulo, SP, Brasil. (e-mail: jotbalbo@usp.br).
}

Manuscrito recebido em 7/12/2008 e aprovado para publicação em $1 / 6 / 2009$. Este artigo é parte de TRANSPORTES, volume XVII, número 2, dezembro de 2009. ISSN: 1415-7713. ocorrendo desde a década de 1980. A partir de então a questão entrou na pauta comum de agentes viários e do meio acadêmico em geral, embora trabalhos anteriores fossem de conhecimento amplo (Bodi et al., 1995; Trichês e Kryckyj, 1999). Existe uma grande demanda por pavimentação urbana nas cidades brasileiras; São Paulo, de acordo com dados da PMSP (1998), possui cerca de $3.000 \mathrm{~km}$ a serem pavimentados. O emprego de RCD gerado em zonas urbanas pode e deve ser uma fonte alternativa de matéria prima para agregados em pavimentação, que considerado um quilômetro de pista simples com duas faixas de rolamento consome cerca de cinco vezes mais agregados que o consumo de uma obra de edifício de apartamentos de 15 andares (Balbo, 2007).

$\mathrm{O}$ uso de agregados reciclados de RCD vem se ampliando, com casos mais recentes de aplicações dos materiais em camadas não tratadas de pavimentos (Dias, 2004; Bernucci et al., 2005; dentre outros), sendo até disponível norma para o emprego do material (PMSP, 2003). Em 28.12.2006, por decreto do executivo da capital paulista, o emprego desses agregados reciclados em pavimentação tornou-se obrigatório. Estima-se que na cidade sejam geradas 17 mil to- 
neladas de entulho de construção civil por dia. No Brasil, caso todo o RCD de origem mineral (61,6 x $10^{6}$ t/ano) fosse empregado como fonte de agregados para a construção civil, a participação seria de 16,2\%, pois o consumo de agregados no país é da ordem de $380 \times 10^{6}$ t/ano. O setor de pavimentação e obras públicas pode consumir em torno de $84 \%$ na geração nacional da fração mineral do RCD (Angulo, 2005). A possibilidade de utilização dos RCD em concretos vem corroborar a necessidade de reduzir custos de obras além de se tratar de uma alternativa que preserva recursos não-renováveis e possibilita a valorização de materiais nobres, destinando-os ao atendimento de demandas sociais urgentes. Este artigo tem por objetivo apresentar resultados de investigação em laboratório de características mecânicas básicas de concretos compactados com rolo (CCR) fabricados com RCD, comparando-as com aquelas de um CCR com agregados pétreos virgens. São também apresentadas algumas características dos agregados de RCD e discutida de que maneira influenciam no comportamento mecânico do CCR. Busca-se desta forma, uma verificação preliminar da viabilidade de uma tecnologia para pavimentação de boa qualidade, menor impacto ambiental e menor custo de execução.

\section{REFERENCIAL TEÓRICO}

Os agregados reciclados empregados nos estudos estavam em conformidade com a NBR 15116 (ABNT, 2004) que especifica critérios para o emprego de agregados reciclados de RCD. A metodologia de amostragem empregada na seleção do RCD foi desenvolvida por Pierre Gy (Pitard, 1993) e se destaca por sua utilidade prática na exploração de jazidas e de minas. A teoria de amostragem de Pierre Gy pressupõe que o material a esteja homogeneizado e que não existam erros inerentes às ferramentas de amostragem ou máquinas de cominuição (Goes et al., 1991). A amostra mínima de agregados reciclados de RCD para o estudo resultou em valor de $535 \mathrm{~kg}$ representativo de cada lote produzido em usina para um dia de trabalhos de pavimentação com CCR, sendo adotadas amostras de $600 \mathrm{~kg}$. Apesar da quantidade menor de pedrisco (404 $\mathrm{kg} / \mathrm{m}^{3}$ ) exigida para as misturas, foram coletadas amostras de mesmo tamanho.

As usinas de reciclagem classificam os agregados reciclados de RCD pela cor predominante: cinza (associado a componentes de natureza cimentícia) e vermelho (predominância de componentes de natureza cerâmica). Sabe-se que o emprego dos agregados reciclados de RCD em muitos tipos de concretos é viável, sendo que um dos aspectos que limitam o seu uso refere-se à heterogeneidade da composição e à variabilidade das propriedades físicas (Carrijo, 2005). Os a- gregados reciclados graúdos de RCD são mais porosos que os agregados naturais de rochas calcárias e ígneas (Cho e Yeo, 2004); tal porosidade reduz a resistência mecânica dos concretos. Por outro lado, as propriedades físicas, como a absorção de água e a massa específica aparente das fases (concreto, argamassa, cerâmica e rocha) do agregado reciclado graúdo de RCD, que estão relacionadas com a porosidade, são muito variáveis. Angulo (2005) esclarece que a separação por fases por meio da “catação” não se apresenta como eficiente para controlar o comportamento dos concretos. São necessárias, portanto, informações detalhadas sobre as características mais relevantes dos agregados reciclados de RCD que controlam o comportamento mecânico dos concretos; isso é condição para aumentar o emprego desses agregados na fabricação de produtos à base de cimento (Carrijo, 2005). A porosidade desses agregados, bem como a influência da densidade na distribuição das fases e na composição química e mineralógica foi correlacionada com o desempenho dos concretos por Angulo (2005). O controle da variabilidade dos agregados reciclados de RCD permite um comportamento mais homogêneo dos materiais; a separação em meio denso é interessante por separar os agregados de RCD reciclados em função da densidade aparente das partículas (Angulo, 2005). O equipamento empregado é o cone de separação densitária sink and float conforme método ASTM C729 - 05 (ASTM, 2004) constituído de dois compartimentos cilíndrico-cônicos ligados por uma calha. Os dois compartimentos possuem peneiras no fundo de seus reservatórios que permitem a circulação do meio denso no sentido do maior para o menor; durante o ensaio, o material mais denso afunda e fica retido na peneira deste compartimento. O material menos denso flutua e é transportado através da calha para o compartimento menor (Luz, 2004).

A polpa do meio denso foi obtida com a mistura de ferro-silício (75\%-25\%) homogeneizada com água até atingir-se o peso específico de $22 \mathrm{kN} / \mathrm{m}^{3}$ recomendado por Angulo (2005) para estudo de concretos. De acordo com o exposto, cinco lotes de agregados reciclados foram ensaiados, sendo selecionados os lotes RCD 1 (mais denso, de coloração cinza), RCD 3 (densidade intermediária, de coloração entre o cinza e o vermelho) e RCD 4 (menos denso, de coloração mais vermelha, com maior quantidade de materiais cerâmicos). Na Tabela 1 são apresentados os resultados da separação densitária para os materiais selecionados, sendo que desta forma poder-se-ia investigar os efeitos do acréscimo gradativo de agregados de RCD originários de componentes cerâmicos como telhas e tijolos.

Na Figura 1 são apresentadas três curvas granulométricas denominadas por Pittman e Ragan (1998) como de granulometrias fina, média e grossa, com di- 
âmetro máximo de $25 \mathrm{~mm}$ para os agregados, para aplicações em CCR. Neste estudo foram adotadas tais curvas de referência em especial porque Abreu (2007) as utilizando obteve elevadas resistências para o CCR em relação a padrões normalmente conhecidos em obras rodoviárias nacionais, e ainda empregando baixos consumos de cimento (menor custo e menores problemas de retração no concreto).

Tabela 1. Separação densitária dos agregados reciclados de RCD

\begin{tabular}{cccc}
\hline Amostra/Origem & $\begin{array}{c}\text { Flutua } \\
\text { (kg/\%) }\end{array}$ & $\begin{array}{c}\text { Afunda } \\
\text { (kg/\%) }\end{array}$ & $\begin{array}{c}\text { Total } \\
(\mathbf{k g} / \%)\end{array}$ \\
\hline $\begin{array}{c}\text { RCD 1 / } \\
\text { Pavimento de concreto }\end{array}$ & $9,80 / 23,63$ & $31,68 / 76,37$ & $41,48 / 100$ \\
\hline $\begin{array}{c}\text { RCD 3 } \\
\text { Misto de demolição }\end{array}$ & $9,84 / 33,77$ & $19,30 / 66,23$ & $29,14 / 100$ \\
\hline $\begin{array}{c}\text { RCD 4 / } \\
\text { Misto de demolição }\end{array}$ & $15,70 / 58,15$ & $11,30 / 41,85$ & $27,00 / 100$ \\
\hline
\end{tabular}

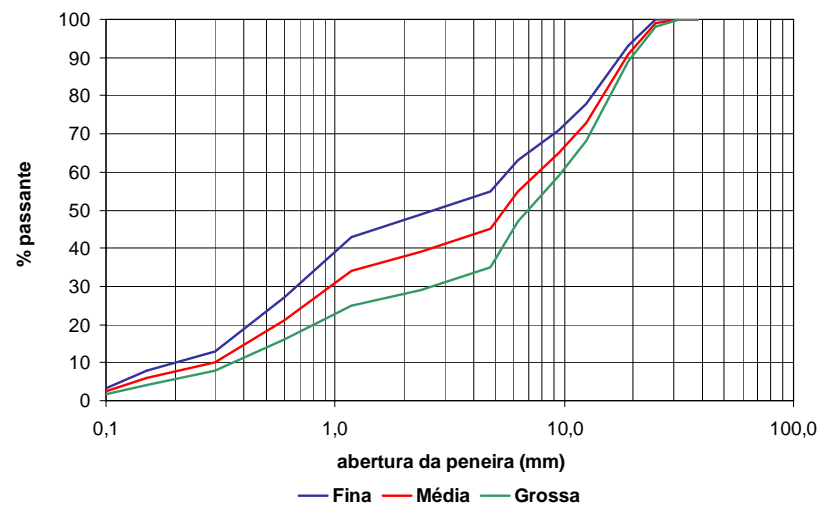

Figura 1. Curvas granulométricas para agregados com diâmetro máximo de 25 mm (Pittman e Ragan, 1998)

\section{METODOLOGIA}

\subsection{Consumo de Ligante Hidráulico e Padrão de Resistência do CCR}

O cimento empregado para a preparação dos CCR foi o CP III E 40 RS (cimento de alto forno ou de baixo calor de hidratação). Para CCR, como base de pavimentos asfálticos rígido-híbridos, fixou-se em 2,5 $\mathrm{N} / \mathrm{mm}^{2}$ a resistência à tração na flexão de dosagem fct,f - aos 28 dias, por tal valor possivelmente atender vários padrões de volume de tráfego comercial (Balbo, 2005). O procedimento de dosagem do CCR com agregados virgens pautou-se pelas diretrizes que se seguem: (a) tomaram-se os consumos de cimento em 90, 110 e $130 \mathrm{~kg} / \mathrm{m}^{3}$ de concreto; (b) o teor de umidade das misturas variou de 5,5 a $7,5 \%$, de meio em meio ponto porcentual; (c) determinou-se o teor de umidade ótima na curva de compactação; (d) foram preparados três corpos-de-prova prismáticos para cada consumo de cimento no respectivo teor de umidade ótima encontrada; (e) determinou-se a curva consumo de cimento versus resistência para a definição da mis- tura piloto. No caso da dosagem do CCR com RCD a faixa de consumo de cimento variou entre 110 e 150 $\mathrm{kg} / \mathrm{m}^{3}$ tendo em vista a expectativa de substituição de $50 \%$ e $100 \%$ dos agregados naturais britados por RCD, para se buscar a mesma resistência do traço piloto com agregados virgens.

\section{2. Índices Físicos dos Agregados Naturais Britados e dos Agregados Reciclados}

Para o CCR produzido com agregados naturais britados foram utilizados quatro tipos de agregados: areia artificial como agregado miúdo, brita zero (pedrisco), brita 1 e brita 2 como agregados graúdos; todos os materiais possuíam origem granítica. Na Tabela 2 são apresentadas algumas características dos agregados naturais britados empregados no estudo. Optou-se para as dosagens do CCR com agregados reciclados de RCD em que a brita zero (pedrisco) fosse uma mistura de reciclado e natural na razão de $50 \%$. Devido ao excesso de material passante na peneira $4,8 \mathrm{~mm}$ da brita reciclada foi necessária uma correção na dosagem onde foi também compensada a fração areia do traço inicial. As frações de britas 1 e 2 foram mantidas em $100 \%$ recicladas nas misturas. Para efeito de estudo, uma dosagem de CCR com $100 \%$ de brita zero reciclada seria produzida; para este caso foi escolhida o lote RCD 4 (Tabela 1) por apresentar uma composição maior de agregados de menor densidade, apresentando maior absorção; o CCR produzido com esta dosagem foi chamado de CCR4-100\%. A usina onde foram coletadas as amostras de agregados reciclados de RCD não produzia brita 1 e brita 2 separadamente. Neste trabalho, foi chamado simplesmente por "brita", a substituição da brita 1 e brita 2 naturais por este material reciclado misturado, fazendo-se as correções necessárias na dosagem. Na Tabela 3 são apresentadas algumas das características físicas dos agregados reciclados de RCD empregados. É digno de nota aqui verificar a elevada absorção dos agregados reciclados (até $10,6 \%$ ) que aumenta na medida em que a quantidade de material cerâmico (vermelho) presente é maior. A densidade dos grãos de agregados de RCD diminui na medida em que há maior presença de componentes cerâmicos (de RCD 1 para RCD 4).

Tabela 2. Índices físicos dos agregados naturais britados

\begin{tabular}{lcccc}
\hline \multicolumn{1}{c}{ Agregado } & Areia & Brita 0 & Brita 1 & Brita 2 \\
\hline Diâmetro Máximo (mm) & 6,3 & 9,5 & 25,0 & 31,5 \\
\hline Módulo de finura & 3,01 & 5,63 & 6,91 & 7,86 \\
\hline Densidade grãos $\left(\mathrm{kN} / \mathrm{m}^{3}\right)$ & 26,1 & 26,5 & 26,5 & 26,9 \\
\hline Massa unitária (kg/dm $\left.{ }^{3}\right)$ & 1,75 & 1,47 & 1,48 & 1,47 \\
\hline Material pulverulento (\%) & 17,9 & 0,7 & 0,8 & 0,4 \\
\hline Absorção (\%) & 1,26 & 1,33 & 0,90 & 0,60 \\
\hline
\end{tabular}


Tabela 3. Principais características físicas dos agregados reciclados

\begin{tabular}{lcccccc}
\hline \multicolumn{1}{c}{ Lotes } & \multicolumn{2}{c}{ RCD 1 } & \multicolumn{2}{c}{ RCD 3 } & \multicolumn{2}{c}{ RCD 4 } \\
\hline \multicolumn{1}{c}{ Agregados } & Brita & Brita 0 & Brita & Brita 0 & Brita & Brita 0 \\
\hline Diâmetro Máximo $(\mathrm{mm})$ & 25,0 & 9,5 & 25,0 & 9,5 & 25,0 & 9,5 \\
\hline Módulo de finura & 7,24 & 5,50 & 7,22 & 5,09 & 7,06 & 4,67 \\
\hline Densidade dos grãos $\left(\mathrm{kN} / \mathrm{m}^{3}\right)$ & 25,4 & 24,5 & 24,3 & 23,5 & 22,9 & 22,9 \\
\hline Massa unitária $\left(\mathrm{kg} / \mathrm{dm}^{3}\right)$ & 1,34 & 1,21 & 1,25 & 1,26 & 1,20 & 1,29 \\
\hline Absorção (\%) & 4,60 & 5,90 & 6,00 & 8,70 & 9,50 & 10,60 \\
\hline
\end{tabular}

\subsection{Dosagem do CCR}

Após definido o consumo de cimento (C) a ser utilizado no traço experimental, calculou-se o peso específico do CCR para diferentes teores de umidade conforme preconizado pelo extinto Departamento Nacional de Estradas de Rodagem (DNER, 1992). Para os CCR com agregados reciclados, devido a sua elevada absorção, o teor de umidade para as curvas de compactação atingiu quase $12 \%$; no caso do concreto com agregados virgens (CCR*) o teor de umidade ótimo resultou 6\%. Durante a moldagem dos concretos com agregados reciclados no teor de umidade ótimo (na energia normal) ocorreu exsudação de água (muito provavelmente associada à quebra de grãos com água em seus poros). Para contornar esta situação foi reduzido de $1 \%$ o valor do teor de umidade de compactação (em relação à umidade ótima) para todos os CCR com agregados de RCD. Na Tabela 4 é apresentada a nomenclatura adotada para os CCR estudados.

\subsection{Determinação do Consumo de Cimento dos CCR}

Na Figura 2 pode ser observado o aumento da resistência à tração na flexão acompanhando o aumento do consumo de cimento para todos os CCR. Os consumos de cimento adotados foram: $110 \mathrm{~kg} / \mathrm{m}^{3}$ para o CCR*; $125 \mathrm{~kg} / \mathrm{m}^{3}$ para os CCR1 e CCR4-100\%; $120 \mathrm{~kg} / \mathrm{m}^{3}$ para os CCR3 e CCR4. Como o estudo privilegiou que para todos os concretos fosse obtida a resistência estabelecida (fct, $f=2,5 \mathrm{~N} / \mathrm{mm}^{2}$ ) foi necessário o aumento do consumo de cimento do CCR3 e do CCR4 em relação ao CCR* de apenas 9\%; para o CCR1 e o CCR4-100\% este aumento foi de 13,5\%. Na Tabela 5 são apresentados os traços definitivos dos concretos; para o CCR* fazem parte da dosagem a areia, a brita 0 , a brita 1 e a brita 2. Para os CCR com RCD fazem parte a areia, a brita 0 (50\% reciclado e $50 \%$ natural) e a brita (aqui denominada como o material resultante da usina de reciclagem compreendendo britas 1 e 2).

Tabela 4. Nomenclatura dos CCR estudados

\begin{tabular}{lcccc}
\hline \multirow{2}{*}{ Designação } & $\begin{array}{c}\text { Agregado } \\
\text { empregado }\end{array}$ & \multicolumn{2}{c}{$\begin{array}{c}\text { Fraçães de } \\
\text { substituição }\end{array}$} & $\begin{array}{c}\text { Teor de umidade } \\
\text { de compactação } \\
\text { (\%) }\end{array}$ \\
\cline { 3 - 4 } & Virgem de granito & \multicolumn{2}{c}{ Mistura de referência } & 6,0 \\
\hline CCR* & RCD1 & 100 & 50 & 8,4 \\
\hline CCR1 & RCD3 & 100 & 50 & 8,8 \\
\hline CCR3 & RCD4 & 100 & 50 & 8,9 \\
\hline CCR4 & RCD4 & 100 & 100 & 10,0 \\
\hline
\end{tabular}

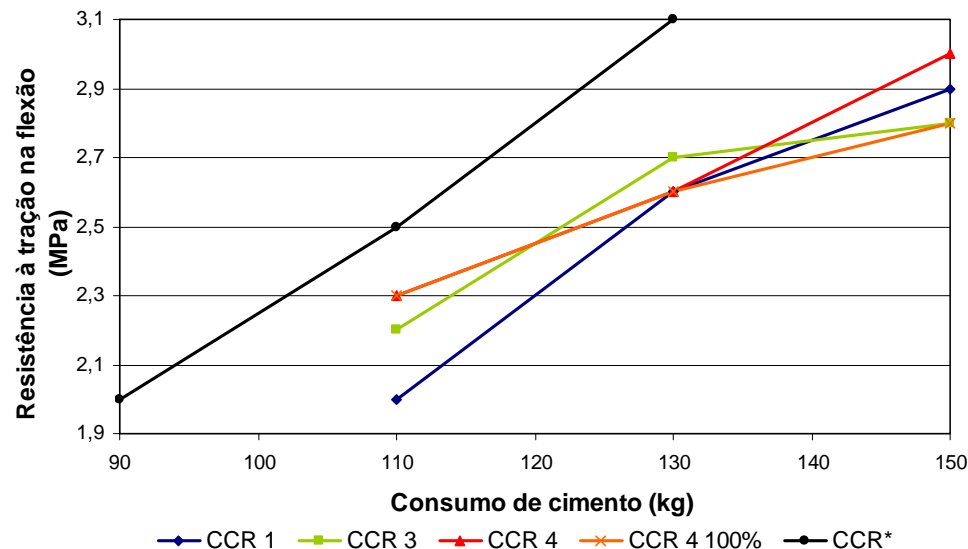

Figura 2. Consumo de cimento $x$ resistência à tração na flexão para todos os CCR estudados 
Tabela 5. Traços em massa definitivos para CCR estudados

\begin{tabular}{|c|c|c|c|c|}
\hline Tipo de CCR & $\begin{array}{l}\text { Consumo de } \\
\text { cimento } \\
\left(\mathrm{kg} / \mathrm{m}^{3}\right)\end{array}$ & Traço unitário em massa & $\begin{array}{c}\text { Teor de umidade } \\
\text { de compactação } \\
\text { (\%) }\end{array}$ & $\begin{array}{c}\gamma_{a s}^{\max } \\
\left(k N / m^{3}\right)\end{array}$ \\
\hline $\mathrm{CCR}^{*}$ & 110 & $1: 8,225: 5,070: 4,290: 1,950$ & 6,0 & 24,25 \\
\hline CCR1 & 125 & $1: 5,546: 4,894: 5,367$ & 8,4 & 23,05 \\
\hline CCR3 & 120 & $1: 5,648: 5,135: 5,295$ & 8,8 & 22,57 \\
\hline CCR4 & 120 & 1: 5,529: 4,880:5,352 & 8,9 & 22,10 \\
\hline CCR4-100\% & 125 & $1: 4,425: 5,365: 4,640$ & 10,0 & 21,36 \\
\hline
\end{tabular}

\subsection{ENSAIOS DE CARACTERIZAÇÃO BÁSICA DOS CONCRETOS}

Até a presente fase desse estudo foram fabricadas amostras de concretos (CCR convencionais e com agregados de RCD) para a avaliação de suas resistências à compressão pela NBR 5739 (ABNT, 2007) e à tração na flexão pela NBR 12142 (ABNT, 1991), bem como uma estimativa de seu módulo de elasticidade pela NBR 15630 (ABNT, 2008). Nesse último caso foi empregado o ensaio de medida de módulo de elasticidade por pulso ultrasônico, empregando-se o equipamento de pulso elétrico de baixa freqüência ultrasônica, com alta estabilidade e precisão de leitura $(\sim 0,1 \mu \mathrm{s})$, transdutor emissor e receptor para transformação do pulso elétrico em onda de choque e novamente em pulso elétrico, e por fim um circuito medidor de tempo de propagação de onda que pode ser lido em mostrador digital. O módulo de elasticidade ultrasônico é calculado por meio do produto do quadrado da velocidade de propagação aferida no meio (no CCR nesse caso) pelo peso específico do material estudado. Observe-se que, por tratar-se de uma medida de módulo de elasticidade dinâmico, os resultados, por analogia ao caso de retroanálises de bacias de deflexões com falling weigth deflectometer, em geral são maiores que aqueles obtidos durante medidas de módulos de elasticidade estáticos durante as quais ocorre, ao longo do ensaio, a plastificação parcial na microestrutura dos materiais.

\section{RESULTADOS DE CARACTERÍSTICAS FÍSICAS E MECÂNICAS DOS CCR}

\subsection{Porosidade e Absorção dos CCR}

Na Tabela 6 são apresentados os resultados de porosidade e de absorção médios para dois corpos-de-prova para cada tipo de CCR estudado. Pode-se verificar que o CCR* com agregados naturais tem absorção e porosidade inferior aos CCR com RCD. Verifica-se ainda que o CCR4-100\% apresentou maior porosidade, sendo $65 \%$ superior ao CCR*. Para os CCR1, CCR3 e CCR4, todos com 100\% de agregados graúdos reciclados e $50 \%$ de agregados miúdos reciclados, a porosidade variou em $20 \%$ do CCR1 para o CCR3 e em $7 \%$ para o CCR4. Para o CCR4-100\% com 100\% de agregados graúdos e miúdos reciclados a porosidade variou em $18 \%$. Observa-se o aumento da porosidade dos concretos com a redução de sua massa específica.

\subsection{Resistência à Compressão dos CCR}

Na Tabela 7 são apresentados os resultados (pela média de seis amostras) de resistência à compressão simples $\left(f_{c d}\right)$ aos 7 e 28 dias para os concretos. O CCR* teve incremento de resistência dos 7 para os 28 dias de 42\%; este incremento, para os CCR1, CCR3, CCR4 e CCR4-100\% foi, respectivamente, de 43\%, 23\%, 18\% e $30 \%$. Verifica-se que o CCR1, (essencialmente resíduo de concreto de cimento Portland, mais denso) não apresentou diferenças no ganho de resistência à com-

Tabela 6. Massa específica aparente seca máxima, absorção, porosidade e umidade dos CCR

\begin{tabular}{lcccc}
\hline \multicolumn{1}{c}{ Tipo de $\boldsymbol{C C R}$} & $\begin{array}{c}\gamma_{\boldsymbol{a s}}{ }^{\max } \\
\left(\mathbf{k} / \mathbf{m}^{3}\right)\end{array}$ & $\begin{array}{c}\text { Absorção } \\
(\%)\end{array}$ & $\begin{array}{c}\text { Porosidade } \\
(\%)\end{array}$ & $\begin{array}{c}\text { Umidade ótima } \\
(\%)\end{array}$ \\
\hline CCR ${ }^{*}$ & 24,25 & 4,8 & 11,2 & 6,0 \\
\hline CCR1 & 23,05 & 6,8 & 14,4 & 8,4 \\
\hline CCR3 & 22,57 & 8,0 & 17,1 & 8,8 \\
\hline CCR4 & 22,10 & 7,2 & 15,4 & 8,9 \\
\hline CCR4 (100\%) & 21,36 & 9,0 & 18,4 & 10,0 \\
\hline
\end{tabular}

Tabela 7. Resistência à compressão dos CCR estudados, em MPa

\begin{tabular}{cccccc}
\hline Idade (dias) & $\begin{array}{c}\boldsymbol{C} \boldsymbol{C R} \boldsymbol{R}^{*} \\
\left(\mathrm{C}=110 \mathrm{~kg} / \mathrm{m}^{3}\right)\end{array}$ & $\begin{array}{c}\boldsymbol{C} \boldsymbol{C R \boldsymbol { 1 }} \\
\left(\mathrm{C}=125 \mathrm{~kg} / \mathrm{m}^{3}\right)\end{array}$ & $\begin{array}{c}\boldsymbol{C} \boldsymbol{C R 3} \\
\left(\mathrm{C}=120 \mathrm{~kg} / \mathrm{m}^{3}\right)\end{array}$ & $\begin{array}{c}\boldsymbol{C C R 4} \\
\left(\mathrm{C}=120 \mathrm{~kg} / \mathrm{m}^{3}\right)\end{array}$ & $\begin{array}{c}\boldsymbol{C C R 4 - 1 0 0 \%} \\
\left(\mathrm{C}=125 \mathrm{~kg} / \mathrm{m}^{3}\right)\end{array}$ \\
\hline 7 & 8,6 & 8,3 & 10,6 & 10,1 & 10,0 \\
\hline 28 & 12,2 & 11,9 & 13,0 & 11,9 & 13,0 \\
\hline
\end{tabular}


pressão nos períodos avaliados em relação ao CCR*; ao contrário dos demais concretos com maior quantidade de reciclados cerâmicos que apresentaram maior ganho de resistência até os 7 dias (CCR 3, CCR 4 e CCR 4-100\%) e sutil aumento aos 28 dias (CCR 3 e CCR4-100\%).

Como visto, a principal alteração de ganho de resistência foi aos 7 dias no caso dos concretos com maior quantidade de agregados de RCD de natureza cerâmica. Assim, embora as resistências finais não apresentem diferenças muito importantes, observando-se todos os casos e tendo em conta o aumento do consumo de cimento para os CCR com RCD, tem-se claro que a presença de RCD com maior quantidade de agregados de origem cerâmica (menos denso) afetou o ganho de resistência de modo mais apreciável aos 7 dias (em 20\%). Uma possível explicação seria a maior quantidade de finos cerâmicos nas misturas, posto que tais finos, presentes inclusive nas frações granulométricas mais grosseiras no momento da elaboração dos concretos, teriam implicado em maior pozolanicidade, ou seja, atuando como material cimentício suplementar. Observa-se que o CCR* e o CCR1 têm aumento de resistência similar em ambas as idades. Ao compararse o CCR* com CCR1 tem-se que para o CCR1 atingir resistência à compressão similar ao CCR* foi necessário o aumento do consumo de cimento de 110 para $125 \mathrm{~kg} / \mathrm{m}^{3}$ (14\%). Nos demais casos, a resistência final foi atingida ou superada mesmo com pequena redução do consumo de cimento para $120 \mathrm{~kg} / \mathrm{m}^{3}$ (9\% de acréscimo em relação ao $\mathrm{CCR}^{*}$ ), exceção ao CCR4-100\% com consumo de $125 \mathrm{~kg} / \mathrm{m}^{3}$. Os resultados indicam o bom potencial, em termos de ganho de resistência à compressão, do uso do CCR com RCD, sendo que inclusive, o emprego de $100 \%$ de brita zero e brita provenientes de RCD não incorreu em perdas de qualidade nas resistências aferidas (CCR4-100\%).

\subsection{Resistência à Tração na Flexão dos CCR}

Na Tabela 8 são apresentados os resultados obtidos (pela média de 6 amostras) de resistência à tração na flexão aos 7 e 28 dias para os CCR estudados. Observa-se novamente maior ganho de resistência aos 7 dias para CCR com RCD em todas as substituições (50\% e $100 \%$ ), inclusive para o CCR1. Isto pode ser entendido pela alteração de consumo de cimento (C) de todos os CCR com RCD em relação ao CCR* pois, nesse caso, a resistência medida é apreciavelmente afetada pela interface pasta/agregado (Metha e Monteiro, 1994); as misturas com maior consumo de cimento, e com suplementos de finos pozolânicos, naturalmente apresentariam zona de transição pasta/agregado melhor desenvolvida em termos de quantidade de ligações de cristais de silicatos de cálcio hidratados. Observe-se que as resistências finais encontradas para os CCR com RCD, com pequenos incrementos no consumo de cimento, atingem valores similares ao CCR*, o que seria um indicador parcial da adequação do CCR com RCD para emprego em bases de pavimentos de concreto ou asfálticos, sem incrementos de custos importantes no que concerne aos consumos de cimento, bem como com possível redução de custos dos agregados de insumo.

\subsection{Módulo de Elasticidade Dinâmico (Ultra- Sônico) dos CCR}

Na Tabela 9 são apresentados os resultados de módulo de elasticidade dinâmico (ultrasônico). Foram ensaiados dois corpos-de-prova prismáticos para cada tipo de agregado estudado nas dosagens dos CCR, totali-

\begin{tabular}{|c|c|c|c|c|c|}
\hline Idade (dias) & $\begin{array}{c}\boldsymbol{C C R}^{*} \\
\left(\mathrm{C}=110 \mathrm{~kg} / \mathrm{m}^{3}\right)\end{array}$ & $\begin{array}{c}\boldsymbol{C C R \boldsymbol { 1 }} \\
\left(\mathrm{C}=125 \mathrm{~kg} / \mathrm{m}^{3}\right)\end{array}$ & $\begin{array}{c}\boldsymbol{C C R} \mathbf{3} \\
\left(\mathrm{C}=120 \mathrm{~kg} / \mathrm{m}^{3}\right)\end{array}$ & $\begin{array}{c}\boldsymbol{C C R} 4 \\
\left(\mathrm{C}=120 \mathrm{~kg} / \mathrm{m}^{3}\right)\end{array}$ & $\begin{array}{c}\text { CCR4-100\% } \\
\left(\mathrm{C}=125 \mathrm{~kg} / \mathrm{m}^{3}\right)\end{array}$ \\
\hline 7 & 1,3 & 1,8 & 2,0 & 2,1 & 1,8 \\
\hline 28 & 2,5 & 2,7 & 2,7 & 2,7 & 2,5 \\
\hline
\end{tabular}

Tabela 9. Módulo de elasticidade com onda ultrasônica

\begin{tabular}{|c|c|c|c|c|c|c|c|c|}
\hline Tipo de CCR & $\begin{array}{c}\text { Comprimento } \\
\text { do } \mathrm{CP} \\
\text { (m) }\end{array}$ & $\begin{array}{c}\text { Largura } \\
\text { do CP } \\
\text { (m) }\end{array}$ & $\begin{array}{c}\text { Altura } \\
\text { do } C P \\
\text { (m) }\end{array}$ & $\begin{array}{c}\text { Massa } \\
\text { do CP } \\
(\mathrm{kg})\end{array}$ & $\begin{array}{c}\text { Massa } \\
\text { especifica } \\
\text { do } C P \\
\left(\mathrm{~kg} / \mathrm{m}^{3}\right) \\
\end{array}$ & $\begin{array}{c}\text { Tempo de } \\
\text { propagação } \\
\text { no meio } \\
(\mu \mathrm{s}) \\
\end{array}$ & $\begin{array}{c}\text { Velocidade } \\
\text { de } \\
\text { propagação } \\
(\mathrm{km} / \mathrm{s}) \\
\end{array}$ & $\begin{array}{c}\text { Módulo de } \\
\text { Elasticidade } \\
\left(M N / m^{2}\right)\end{array}$ \\
\hline \multirow{2}{*}{$\mathrm{CCR}^{*}$} & 0,4000 & 0,1000 & 0,1020 & 9,385 & $2.300,25$ & 107,6 & 3,717472 & 31.788 \\
\hline & 0,4025 & 0,1000 & 0,1030 & 9,443 & $2.277,75$ & 111,7 & 3,603402 & 29.576 \\
\hline \multirow{2}{*}{ CCR1 } & 0,4010 & 0,0995 & 0,1020 & 9,005 & $2.212,67$ & 120,5 & 3,327801 & 24.504 \\
\hline & 0,4015 & 0,1025 & 0,1010 & 9,076 & $2.183,55$ & 115,5 & 3,476190 & 26.386 \\
\hline \multirow{2}{*}{ CCR3 } & 0,4010 & 0,1000 & 0,1015 & 8,729 & $2.144,64$ & 128,5 & 3,120623 & 20.885 \\
\hline & 0,3995 & 0,1005 & 0,1020 & 8,807 & $2.150,53$ & 130,2 & 3,068356 & 20.247 \\
\hline \multirow{2}{*}{ CCR4 } & 0,3970 & 0,1005 & 0,1025 & 8,580 & $2.098,01$ & 124,4 & 3,191318 & 21.367 \\
\hline & 0,4015 & 0,1010 & 0,1035 & 8,822 & $2.101,94$ & 128,3 & 3,129384 & 20.584 \\
\hline \multirow{2}{*}{ CCR4-100\% } & 0,4005 & 0,1005 & 0,1035 & 8,295 & $1.991,17$ & 139,4 & 2,873027 & 16.436 \\
\hline & 0,4010 & 0,1000 & 0,1030 & 8,404 & $2.034,72$ & 137,6 & 2,914244 & 17.281 \\
\hline
\end{tabular}


zando dez exemplares. Os resultados indicam clara redução nos valores de módulo de elasticidade para os CCR mais porosos.

\section{DISCUSSÃO DOS RESULTADOS}

Segundo Alaejos et al. (2004) um concreto plástico com $\mathrm{f}_{\mathrm{cd}}$ de 25 a $50 \mathrm{MPa}$ pode perder até $30 \%$ dessa resistência quando tem $100 \%$ de seus agregados substituídos por agregados de RCD. Assim, o consumo de cimento, para uma mesma resistência, é maior para os concretos com agregados de RCD, sendo que este aumento pode variar de 7 a $17 \%$. Para o CCR4-100\% estudado verificou-se um acréscimo de consumo de cimento de 14\% confirmando esta expectativa anterior. Para substituições de até $50 \%$ dos agregados naturais por RCD, a perda de resistência é de 5 a $10 \%$. Os CCR1, CCR3 e o CCR4 tiveram acréscimo de $9 \%$ no consumo de cimento. Observou-se nesse estudo que os valores de resistência à compressão nos CCR reciclados foram semelhantes ao CCR*; contudo, a resistência à compressão pouca informação pode trazer sobre o possível desempenho do material como camada de pavimento, pois o mesmo trabalha em flexão. A resistência à tração na flexão $\left(\mathrm{f}_{\mathrm{ct}, \mathrm{f}}\right)$ é um importante indicador da viabilidade do emprego do material cimentado em camadas de pavimentos. Neste caso, houve aumento significativo na resistência dos CCR reciclados aos 7 dias, embora aos 28 dias tenham as mesmas mantido-se praticamente idênticas ao CCR*. Deve ser considerado que para se atingir tais resultados foram pequenos os acréscimos de consumo de cimento nas misturas (9\%). Todavia, a resistência estática por si mesma não traz informação específica a respeito do comportamento à fadiga do material, que é de fundamental conhecimento para o projeto de pavimentos, definindo as espessuras de camadas de CCR viáveis para determinada estrutura de pavimento e determinado tráfego de projeto. Também não afere, como para qualquer outro material de pavimentação, sua capacidade de carga. Nesse aspecto, algo que interfere bastante na resposta estrutural do material em pista bem como no desempenho dos CCR em pavimentos é o seu módulo de elasticidade.

Ainda segundo Alaejos et al. (2004) um concreto convencional pode sofrer redução em até $40 \%$ do valor de seu módulo de elasticidade quando tem 100\% de seus agregados substituídos por agregados reciclados de RCD. Para o CCR4 (100\%) estudado, verificou-se decréscimo no valor do módulo de elasticidade dinâmico $\left(E_{\text {din }}\right)$ em relação ao $\mathrm{CCR}^{*}$ de $45 \%$ confirmando esta expectativa. Para concretos com $50 \%$ dos agregados naturais britados substituídos por agregados reciclados a redução do módulo de elasticidade foi de cerca de $20 \%$ para o CCR1, sendo que a para os
CCR3 e CCR4 foi de aproximadamente 32\%. Para concretos empregando agregados reciclados de concretos e de argamassas a redução do módulo de elasticidade se deve à camada de argamassa antiga aderida ao agregado original e à maior porosidade dos agregados reciclados (Levy, 1997). Para agregados reciclados de origem cerâmica, a redução do módulo está relacionada com a porosidade dos agregados. Quanto menos densos são os agregados constituintes do concreto, maior será a redução do módulo de elasticidade; conseqüentemente o valor do módulo de elasticidade sofre uma redução à medida que o concreto apresenta valores menores de massa específica aparente seca. $\mathrm{Na}$ Figura 3 é confirmada a dependência entre a porosidade do concreto e a redução do módulo de elasticidade dos CCR estudados. Verifica-se que o CCR4$100 \%$ apresenta $55 \%$ do valor do módulo de elasticidade do CCR* e acréscimo de $65 \%$ em relação à sua porosidade.

Na Figura 4 é apresentada correlação entre a massa específica aparente seca e o módulo de elasticidade do CCR. A massa especifica do CCR4-100\% é 12\% inferior ao CCR* porém a diferença entre os valores de módulo de elasticidade foi de 55\%, ou seja, pequena queda na massa específica resultou em grande redução no valor do módulo de elasticidade.

Na Figura 5 são confrontados valores de $E_{\text {din }}$ e $f_{c t, f}$ dos CCR. Muito embora a resistência seja quase constante, apesar do pequeno incremento de consumo

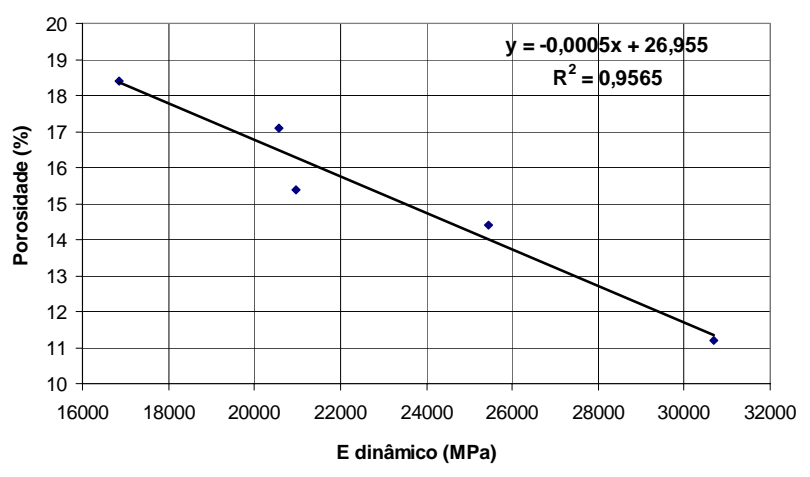

Figura 3. Correlação entre porosidade e o módulo de elasticidade dos CRR estudados

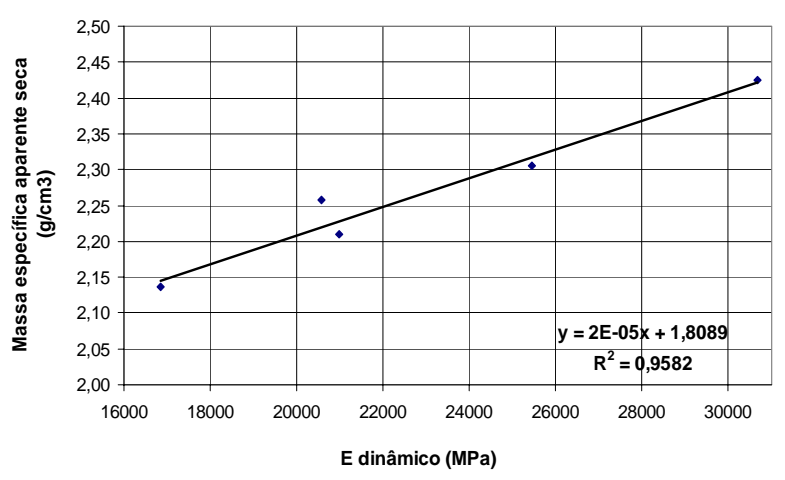

Figura 4. Correlação entre massa específica e o módulo de elasticidade dos CRR estudados 


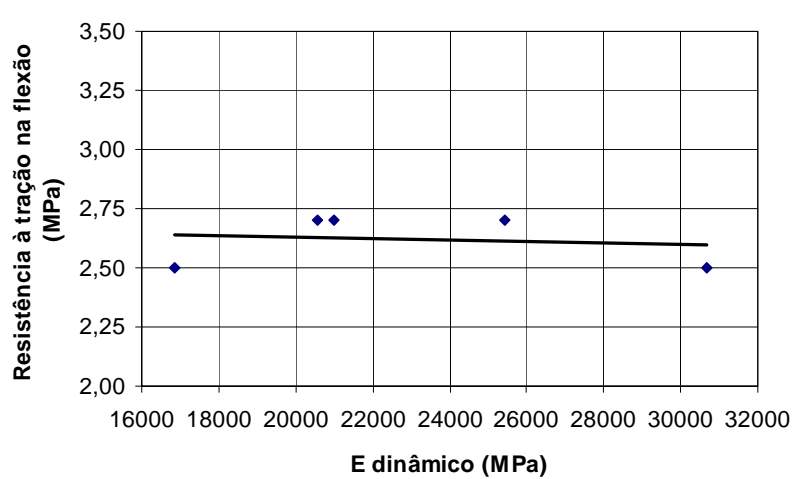

Figura 5. Relação entre a resistência à tração na flexão e o módulo de elasticidade dos CCR

de cimento nos CCR com agregados reciclados, cabe observar que não foi encontrada a variabilidade normalmente relatada do módulo de elasticidade em função da resistência dos concretos. Embora ocorra queda expressiva no valor de $\mathrm{E}_{\mathrm{din}}$, as resistências, para materiais semelhantes em vários aspectos, mantiveram-se semelhantes. Tem-se o oposto do caso dos aços de construção civil, cujo módulo de elasticidade permanece praticamente constante embora possam ser fabricados com resistências muito diferentes. Este comportamento dos concretos estudados possui importantes impactos na avaliação de seu emprego em pavimentação. As camadas cimentadas trabalham em flexão sob a ação de cargas; o fato de uma camada cimentada apresentar menor módulo de elasticidade tem conseqüências, em especial quando empregada como base de pavimentos asfálticos semi-rígidos ou rígido-híbridos (BALBO, 2005). Em um sistema de três camadas, por simplicidade, no qual sejam mantidas suas espessuras, a carga aplicada e os módulos de elasticidade do revestimento (mistura asfáltica densa) e do subleito, tolerando-se variações no módulo de elasticidade da base, na medida em que este último diminui as tensões de tração na flexão na camada também diminuem.

O CCR com menor módulo de elasticidade foi aquele que apresentou maior porosidade, conforme Tabelas 6 e 9 anteriores. Refletindo sobre o comportamento à fratura do material, sendo que processo de fratura e propagação de fissuras é muito dependente dos vazios preexistentes, que são imperfeições na matéria (Balbo, 2007), quanto maior a presença de fissuras ou vazios iniciais, maior a probabilidade de fratura precoce. Sendo assim, reforça-se aqui a imperiosa necessidade de estudos sistemáticos de comportamento à fadiga dos CCR com RCD, evitando-se estabelecer conclusões prematuras. Por outro lado, o CCR é um concreto que oferece grande versatilidade em seu emprego em relação a concretos vibrados; por exemplo, com aumento de energia de compactação e simultânea redução da umidade de dosagem da mistura (redução da porosidade da mistura, ganho de massa específica aparente seca, maior empacotamento da mistura), são possíveis melhorias significativas em suas características mecânicas. Embora o teste de pulso ultrasônico meça fisicamente um valor de módulo de elasticidade do material, que é bastante baseado em sua homogeneidade, o que interfere na velocidade da onda, bem como depende da própria rigidez e estrutura dos agregados, os valores apresentados são úteis para indicar diferenças evidentes entre os materiais testados, não sendo diretamente aplicáveis a problemas de engenharia, conforme ressaltam Komlos et al. (1996).

\section{CONCLUSÕES}

Com base nos estudos realizados com os CCR elaborados com agregados reciclados de RCD, foi possível estabelecer as seguintes conclusões:

- As resistências à compressão e à tração na flexão dos CCR empregando 100\% de agregado graúdo reciclado e $50 \%$ de pedrisco reciclado foram próximas às resistências de um CCR com agregados de granito à custa de mais $9 \%$ de ligante hidráulico.

- Para os CCR com RCD foi verificada necessidade de compactação empregando teor de umidade maior como conseqüência da maior porosidade dos agregados reciclados.

- Ao se empregar $100 \%$ de reciclados de RCD em todas as frações, excluída a areia, não foram obtidas diferenças importantes, fossem de dosagem, fossem de resistências.

- A porosidade e a absorção dos CCR estudados aumentaram de modo consistente com o consumo de agregados reciclados bem como em função da diminuição da densidade dos grãos desses agregados.

- Os valores de módulo de elasticidade apresentam estrita relação com a porosidade e com a massa específica dos CCR, tendo ocorrido queda expressiva em seus valores (de 31 GPa para $17 \mathrm{GPa}$, ou 55\%) com a adição dos agregados reciclados.

- Embora a presença de agregados reciclados tenha interferido fortemente no comportamento elástico dos CCR, suas resistências pouco ou nada se diferenciaram, consideradas as pequenas correções de consumo de cimento efetuadas.

Os testes revelaram um grande paralelismo de características entre os CCR confeccionados com agregados reciclados de RCD e o CCR convencional. Também, a substituição de $100 \%$ dos agregados graúdos e pedrisco se mostrou viável em termos de resistência, mas com alterações grandes em sua porosidade 
e módulo de elasticidade. Os resultados indicados no trabalho permitem entender que a pavimentação em concreto trata-se de mais um foco de emprego potencial dos agregados reciclados de resíduos de construção e de demolição como produto final e sustentável ambientalmente. Uma possível vantagem dos CCR com agregados reciclados de RCD, para o caso de pavimentos e pisos em que não fossem prioritárias as cargas repetitivas, seria a combinação de módulos de elasticidade inferiores para uma mesma resistência à tração, o que apontaria para a mistura RCD 4-100\% como mais vantajosa. Apesar disso, deverão ser realizados testes de fadiga nos diversos CCR, pois há que se considerar também que com agregados mais frágeis e com maior porosidade há possibilidades de um comportamento à fadiga menos satisfatório, que passaria a depender não apenas das ligações na interface pasta/agregado mas também da resistência do próprio agregado.

\section{REFERÊNCIAS BIBLIOGRÁFICAS}

Abreu, J. V. (2002) Estudo do concreto de alta resistência compactado com rolo para pavimentação. Dissertação (Mestrado), Escola Politécnica, Universidade de São Paulo, São Paulo.

Alaejos, P.; Sánchez, M.; Dapena, E (2004) Draft of Spanish regulations for the use of recycled aggregate in the production of structural concrete. In: Proceedings of the International RILEM Conference on the use of recycled materials in buildings and structures, p. 511-525.

Angulo, S. C. (2005) Caracterização de agregados reciclados de resíduos da construção e demolição reciclados e a influência de suas características no comportamento de concretos. Tese (Doutorado), Escola Politécnica, Universidade de São Paulo, São Paulo.

Associação Brasileira de Normas Técnicas (1991) NBR 12142: Concreto Determinação da resistência à tração na flexão em corpos-deprova prismáticos. Rio de Janeiro.

Associação Brasileira de Normas Técnicas (2004) NBR 15116: Agregados reciclados de resíduos sólidos da construção civil - Utilização em pavimentação e preparo de concreto sem função estrutural - Requisitos. Rio de Janeiro.

Associação Brasileira de Normas Técnicas (2007) NBR 5739: Concreto Ensaio de compressão de corpos-de-prova cilíndricos. Rio de Janeiro.

Associação Brasileira de Normas Técnicas (2008) NBR15630: Argamassa para assentamento e revestimento de paredes e tetos - Determinação do módulo de elasticidade dinâmico através da propagação de onda ultra-sônica. Rio de Janeiro.

American Society for Testing and Materials (2004) ASTM C729 - 05 Standard Test Method for Density of Glass by the Sink-Float Comparator. Annual Book of ASTM Standards, Volume 04.03.

Balbo, J. T. (2005) Pavimentos asfálticos híbrido-rígidos: Perspectivas para baixos a elevados volumes de tráfego. In: Anais da $36^{\circ} R A P v$ (Cd-rom), Curitiba.

Balbo, J. T. (2007) Pavimentação asfáltica: materiais, projeto e restauração. Ed. Oficina de Textos, São Paulo.

Balbo, J. T. (2006) Britas graduadas tratadas com cimento. Uma avaliação de sua durabilidade sob o enfoque de porosidade, tenacidade e fratura. Transportes, ANPET, Volume XIV, n. 1, p. 46-54.

Bernucci, L. L. B., Leite, F. C., Motta, R. S. (2005) Aplicação de agregado reciclado de RCD em pavimentação: sistema viário da USP-Leste. In: Seminário Gestão e Reciclagem de Resíduos de Construção e Demolição Avanços e Desafios, (Cd-rom), São Paulo.

Bodi, J.; Brito Filho, J. A.; Almeida, S. (1995) Utilização de entulho de construção civil reciclado na pavimentação urbana. In: Anais da 25. . RAPv, Rio de Janeiro, ABPv, p. 409-436.

Bolis, B; Di Renzo, A. (1949) Pavimentazioni stradali. Editore Ulrico Hoelpi, Milano.

Carrijo, P. M. (2005) Análise da massa específica de agregados graúdos provenientes de resíduos da construção e demolição no desempe- nho mecânico do concreto. Tese (Doutorado), Escola Politécnica, Universidade de São Paulo, São Paulo.

Cho,Y. H; Yeo, S. H. (2004) Application of recycled waste aggregate to lean concrete subbase in highway pavement. Canadian Journal of Civil Engineering, v. 31, n. 6, p.p. 1101-1108.

Conselho Nacional do Meio Ambiente (2002) Resolução CONAMA $n^{\circ}$ 307, de 5 de julho de 2002. Disponível em: <http://www.mma.gov.br/port/conama/res/res02/res30702.html>. Acesso em 28 nov. 2007.

Dias, J. F. (2004) Avaliação de resíduos da fabricação de telhas cerâmicas como contribuição para seu emprego em camadas de pavimento de baixo custo. Tese (Doutorado), Escola Politécnica, Universidade de São Paulo, São Paulo.

Departamento Nacional de Estradas de Rodagem (1992) Manual de pavimentos de concreto rolado. Vol. 2, Instituto de Pesquisas Rodoviárias, Rio de Janeiro.

Góes, M.A.C. de; Luz, A.B.; Possa, M.V. (2002) Amostragem. CT2002118-00 Comunicação Técnica elaborada para a 3a Edição do Livro de Tratamento de Minérios, Centro de Tecnologia Mineral, Ministério da Ciência e Tecnologia, Coordenação de Inovação Tecnológica. Rio de Janeiro.

Komlos, K.; Popovics, S.; Niirnbergeroh, T.; Babd, B.; Popovics, J. S. (1996) Ultrasonic Pulse Velocity Test of Concrete Properties as Specified in Various Standards. Cement and Concrete Composites 18, pp. 357-364.

Levy, S. M. (1997) Reciclagem do entulho de construção civil, para utilização como agregado de argamassas e concretos. Dissertação (Mestrado), Escola Politécnica, Universidade de São Paulo, São Paulo.

Luz, A. B. (2004) Tratamento de minérios. 4a. ed., CETEM/CNPq/MCT, Rio de Janeiro.

Metha, K; Monteiro, J. M. (1994) Concreto: estrutura, propriedades e materiais. Editora Pini, São Paulo.

Pitard, F.F. Pierre Gy's Sampling Theory and Sampling Practice: heterogeneity, sampling correctness and statistical process control. ISBN 0-8493-8917-8, CRC Press LLC, $2^{\text {nd }}$. Edition, Boca-Raton, 1993.

Pittman, D. W.; Ragan, S. A. (1998) Drying shrinkage of roller compacted concrete for pavement applications. ACI Materials Journal, v. 95, n.1, p.p. 19-25, Detroit.

Prefeitura do Município de São Paulo (1998) São Paulo em números. Disponível em: <http://portal.prefeitura.sp.gov.br/secretarias /planejamento/sp_em_numeros>. Acesso em 18 out. 2007.

Prefeitura do Município de São Paulo (2003) Camadas de reforço do subleito, sub-base e base mista de pavimento com agregado reciclado de resíduos sólidos da construção civil. PMSP/SP ETS 001/2003, São Paulo.

Trichês, G., Kryckyj, P. R. (1999) Aproveitamento de entulho da construção civil na pavimentação urbana. In: Anais do Congresso Brasileiro de Geotecnia Ambiental, v. 4, p.259-265, São José dos Campos. 